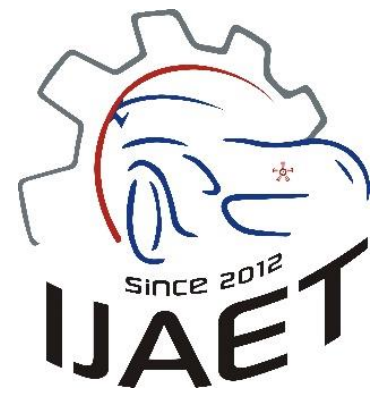

e-ISSN: 2146 - 9067

International Journal of Automotive

Engineering and Technologies

journal homepage:

https://dergipark.org.tr/en/pub/ijaet

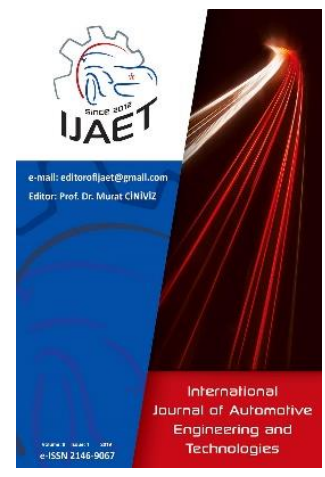

Original Research Article

\title{
Direct torque control of permanent magnet synchronous motor for electric vehicles
}

\author{
Barış Çavuş ${ }^{1}, *$, Mustafa Aktaş² \\ ${ }^{1,2}$ Department of Electrical and Electronics Engineering, Ondokuz Mayıs University, Samsun, Turkey
}

ARTICLE INFO
${ }^{1}$ 0000-0002-5798-8350
${ }^{2}$ 0000-0002-2608-1000
* Corresponding author
baris.cavus@omu.edu.tr

Received: Oct 15, 2019

Accepted: Fab 26, 2020

Published by Editorial Board Members of IJAET

(C) This article is distributed by Turk Journal Park System under the $\mathrm{CC} 4.0$ terms and conditions.

\begin{abstract}
Permanent magnet synchronous motors (PMSM) are highly preferred in electric vehicles due to their high efficiency, good torque-speed characteristics, simple structure and long life. In this paper, the simulation study of direct torque controlled PMSM for electric vehicles was performed in MATLAB by direct torque control (DTC) method using different speed control and speed estimation methods, because output parameters of DTC method such as torque and current, have high ripple, and this ripple should be reduced for electric vehicle. Due to the simple structure of the DTC and its low dependence on the system parameters, it is widely used in alternative current motors. When DTC is used in PMSM drive, it is known that although it has fast dynamic response when it is compared to other vector control methods, the ripple in the torque and flux increases. In this study, direct torque controlled PMSM is tried to be minimized by using different speed control methods and speed estimation methods. For this purpose, proportionalintegral (PI), fuzzy logic and sliding mode speed controller are used as speed controllers and their performances are compared. In addition, speed sensor less direct torque control of PMSM was performed by using sliding mode observer and model reference adaptive system (MRAS) observer. As a result of the simulation studies, it was found that sliding mode speed control method provides less ripples in the torque, better speed control and less energy consumption. Furthermore, as a speed observer, the sliding observer gives better results in speed estimation and provides less energy consumption.

Keywords: electric vehicle, permanent magnet synchronous motor, direct torque control, fuzzy logic controller, sliding mode controller, sliding mode observer, model reference adaptive system
\end{abstract}

\section{Introduction}

Electric vehicles are very important when considering the environmental negative effects of internal combustion engines. In addition, the control of the motor used in electric vehicles is better than control of the internal combustion engine. Therefore, permanent magnet synchronous motor (PMSM) is widely used in electric vehicles [1]. The reasons for the widespread use of PMSM are its small size, high speed response, high efficiency, low inertia and maintenance-cost [2]. In addition, in recent years, the price of the materials such as magnet has decreased considerably [3]. High efficiency and cost are also important for electric vehicles because they directly affect electric motor and battery size and, vehicle cost. Furthermore, compared to other machines, vector control 
methods are easier to apply to PMSM [4].

Permanent magnets that are embedded into the rotor of PMSM create a constant magnetic field in airgap. The three-phase windings in the stator are connected to an AC source to produce a rotating magnetic field. At synchronous speed, the rotor poles are locked into the rotating magnetic field and PMSM operation is performed [5].

Direct torque control (DTC) has been proposed as one of the most suitable methods for achieving high performance in PMSM and other alternating current motors in studies in the literature [6-8]. The advantages of DTC are simple structure, less parameter dependence and fast dynamic response etc. However, DTC has some disadvantages such as variable switching frequency, high ripple in torque and flux [9]. Ripple in torque causes vibrations in the motor. Therefore, most of the studies in the literature aimed to eliminate these disadvantages [10-12]. In the DTC method, the three-phase axis is transformed into 2-phase axis using Park transformation. With the conversion made, the PMSM can be similar with the DC motor in terms of structure and control scheme. One of the transformed phases is used for flux control and the other phase is used for torque control [13].

Although PI control is generally used for speed control of PMSM because of its simplicity, this control method has disadvantages such as high ripples, dependence on system parameters, robust less and etc. [14] For this reason, advanced speed control methods have been proposed which are less affected by system changes and give better results in speed control although they are more complex. In this study, fuzzy logic and sliding mode which are the most commonly used for speed control are used [15, 16].

For speed and torque control of the PMSM, speed and position of motor must be determined by sensor. However, because of the high cost of sensors, speed control without sensors has come into prominence [17]. For this reason, different speed estimation methods have been proposed [18-20]. In this study, the most widely used sliding mode observer and model reference adaptive system (MRAS) were used.

In this study, direct torque control of PMSM was performed in MATLAB by using different speed control methods and speed estimation methods. For this purpose, PI, fuzzy logic and sliding mode controller were used as speed controllers. In addition, direct torque control of the PMSM without speed sensor was performed by using sliding mode and MRAS observer. As a result of the simulation studies, current, speed and torque curves of the PMSM were obtained and speed control and estimation methods were compared each other separately.

\section{Direct Torque Control of PMSM}

\subsection{Mathematical model}

The mathematical model of the PMSM, according to the rotor reference system, is given below [21].

$\frac{d i_{d}}{d t}=-\frac{R}{L_{d}} i_{d}+\frac{\omega_{r} L_{q} i_{q}}{L_{d}}+\frac{V_{d}}{L_{d}}$

$\frac{d i_{q}}{d t}=-\frac{R}{L_{q}} i_{q}-\frac{\omega_{r} L_{d} i_{d}}{L_{q}}-\frac{\psi_{m}}{L_{q}}+\frac{V_{q}}{L_{q}}$

$\psi_{d}=L_{d} I_{d}+\psi_{m}$

$\psi_{q}=L_{q} I_{q}$

$T_{e}=\frac{3 p}{2}\left(\psi_{m} I_{q}+\left(L_{d-} L_{q}\right) I_{d} I_{q}\right)$

$\omega_{r}=\frac{1}{B}\left(J \frac{d \omega_{r}}{d t}-T_{e}+T_{y}\right)$

In the equations given above, $V_{d}$ and $V_{q}$ are $\mathrm{d}$ and q components of stator voltage, $I_{d}$ and $I_{q}$ are $\mathrm{d}$ and q components of stator current, $\psi_{d}$ and $\psi_{q}$ are $\mathrm{d}$ and q components of stator flux, $\psi_{m}$ is flux value of permanent magnet, $T_{e}$ is induced torque, $T_{y}$ is load torque and $\omega_{r}$ is rotor mechanical speed.

\subsection{Direct torque control}

The conventional DTC model is shown in Figure 1. In this method, the current and voltage of the PMSM are measured. Using the measured values, the flux, torque and sector of the motor are calculated. The flux error obtained using the difference between the estimated and the reference flux is input of two-level hysteresis controller. Similarly, the torque error obtained using the difference between the estimated and the reference torque is passed through the 3level hysteresis controller. By using the sector estimated by the signals obtained from hysteresis control units, the necessary switching signals are generated to apply the inverter of the motor.

The hysteresis curves used for 2-level flux and 3-level torque hysteresis control are given in Figure 2.a and 2.b. 


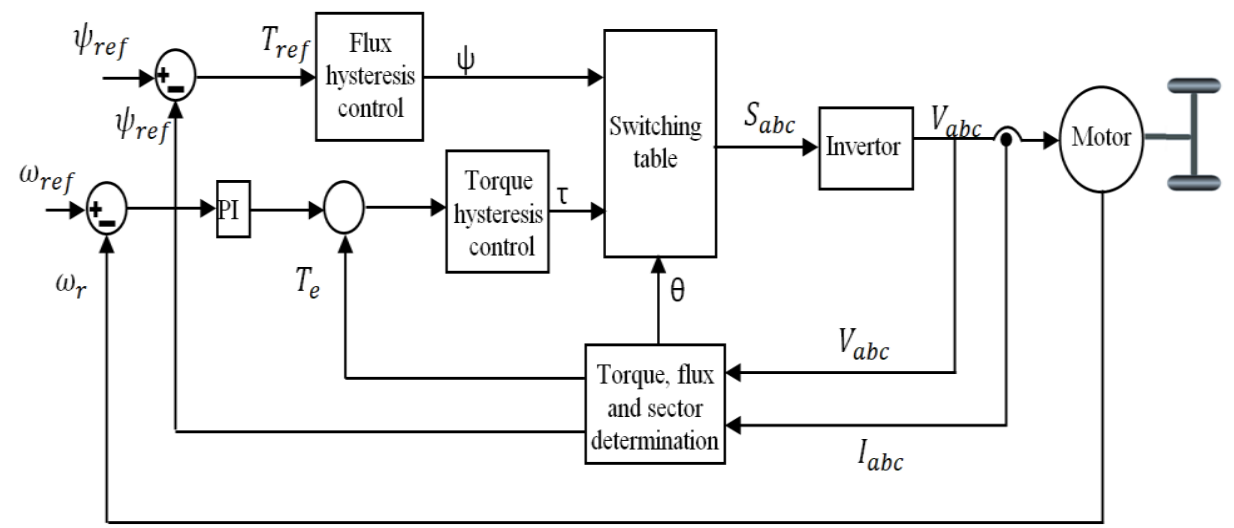

Figure 1. DTC block diagram for EV Applications

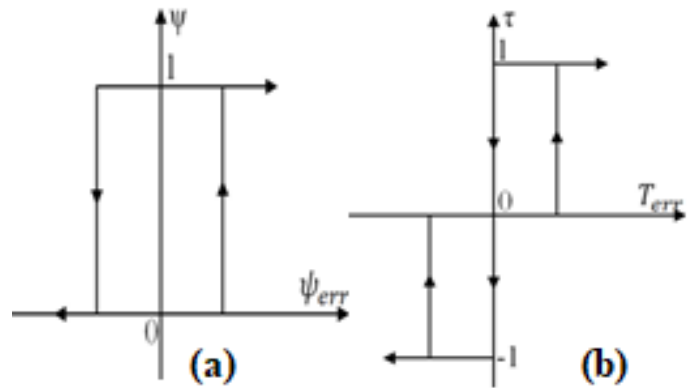

Figure 2. a) Flux 2-level hysteresis curve b) Torque 3-level hysteresis curve

Table 1 can be used to determine the sector with the help of $d$ and $q$ components of the predicted flux of the motor. However, $d$ and q components of the predicted flux are not sufficient to decide the sector. Therefore, in addition to these two criteria, another criterion is added to Table 1.

Table 1. Estimation of sector in DTC of PMSM

\begin{tabular}{|c|c|c|c|c|c|c|c|}
\hline \multicolumn{2}{|c|}{ Sector } & $\overline{\theta(1)}$ & $\theta(2)$ & $\theta(3)$ & $\theta(4)$ & $\theta(5)$ & $\theta(6)$ \\
\hline \multicolumn{2}{|c|}{ Sign of $\psi_{d}$} & + & + & - & - & - & + \\
\hline \multicolumn{2}{|c|}{ Sign of $\psi_{q}$} & $+/-$ & + & + & $+/-$ & - & - \\
\hline \multicolumn{2}{|c|}{$\begin{array}{l}\text { Sign of } \\
\sqrt{3}\left|\psi_{q}\right|-\end{array}$} & - & + & + & - & + & + \\
\hline & & \multicolumn{6}{|c|}{ Table 2. Switching signals } \\
\hline & & $\theta(1)$ & $\theta(2)$ & $\theta(3)$ & $\theta(4)$ & $\Theta(5)$ & $\theta(6)$ \\
\hline \multirow{3}{*}{$\Psi=1$} & $\tau=1$ & $V_{6}$ & $V_{2}$ & $V_{3}$ & $V_{1}$ & $V_{5}$ & $V_{4}$ \\
\hline & $\tau=0$ & $V_{7}$ & $V_{0}$ & $V_{7}$ & $V_{0}$ & $V_{7}$ & $V_{0}$ \\
\hline & $\tau=-1$ & $V_{5}$ & $V_{4}$ & $V_{6}$ & $V_{2}$ & $V_{3}$ & $V_{1}$ \\
\hline \multirow{3}{*}{$\Psi=0$} & $\tau=1$ & $V_{2}$ & $V_{3}$ & $V_{1}$ & $V_{5}$ & $V_{4}$ & $V_{6}$ \\
\hline & $\tau=0$ & $V_{0}$ & $V_{7}$ & $V_{0}$ & $V_{7}$ & $V_{0}$ & $V_{7}$ \\
\hline & $\tau=-1$ & $V_{1}$ & $V_{5}$ & $V_{4}$ & $V_{6}$ & $V_{2}$ & $V_{3}$ \\
\hline
\end{tabular}

The $\tau$ signal which is obtained from the flux hysteresis control unit, the $\psi$ signal which is obtained from the torque hysteresis control unit and obtained sector information are used to obtain the switching signal to be applied to the inverter. Table 2 can be used to obtain the switching signal [22]. According to $\Psi, \tau$ and sector, all switching signals given in Table 2 are shown in Figure 3.

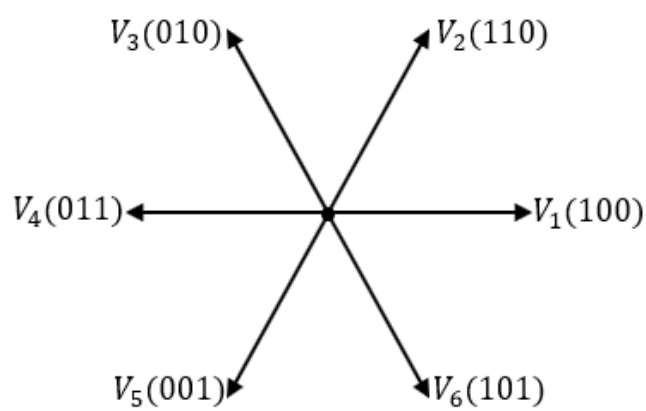

Figure 3. Switching vectors

\subsection{Speed control methods}

In this study, the mathematical models of PI, fuzzy logic and sliding mode controller used as speed controller when direct torque control of PMSM is performed are given.

The reference torque obtained for PI speed controller is given below.

$$
\begin{gathered}
T_{\text {ref }}=K_{p}\left(\omega_{\text {ref }}-\omega_{r}\right)+K_{I} \int\left(\omega_{\text {ref }}-\right. \\
\left.\omega_{r}\right) d t
\end{gathered}
$$

\subsubsection{Fuzzy controller}

Fuzzy logic controller is a theorem based on a set of fuzzy rules [23]. In this method, input and output variables must be determined carefully. In this study, speed error $e\left(\omega_{\text {ref }}-\omega_{r}\right)$ and change in speed error $d e$ are determined as input, and output is determined as the change of PI controller constants $\left(\Delta K_{p}\right.$ and $\left.\Delta K_{I}\right)$.

Membership functions of input and output parameters are given below.

Rule table for $\Delta K_{p}$ and $\Delta K_{I}$, which will be 
determined according to the membership functions given in Figure 4, is given in Table 3 and 4.
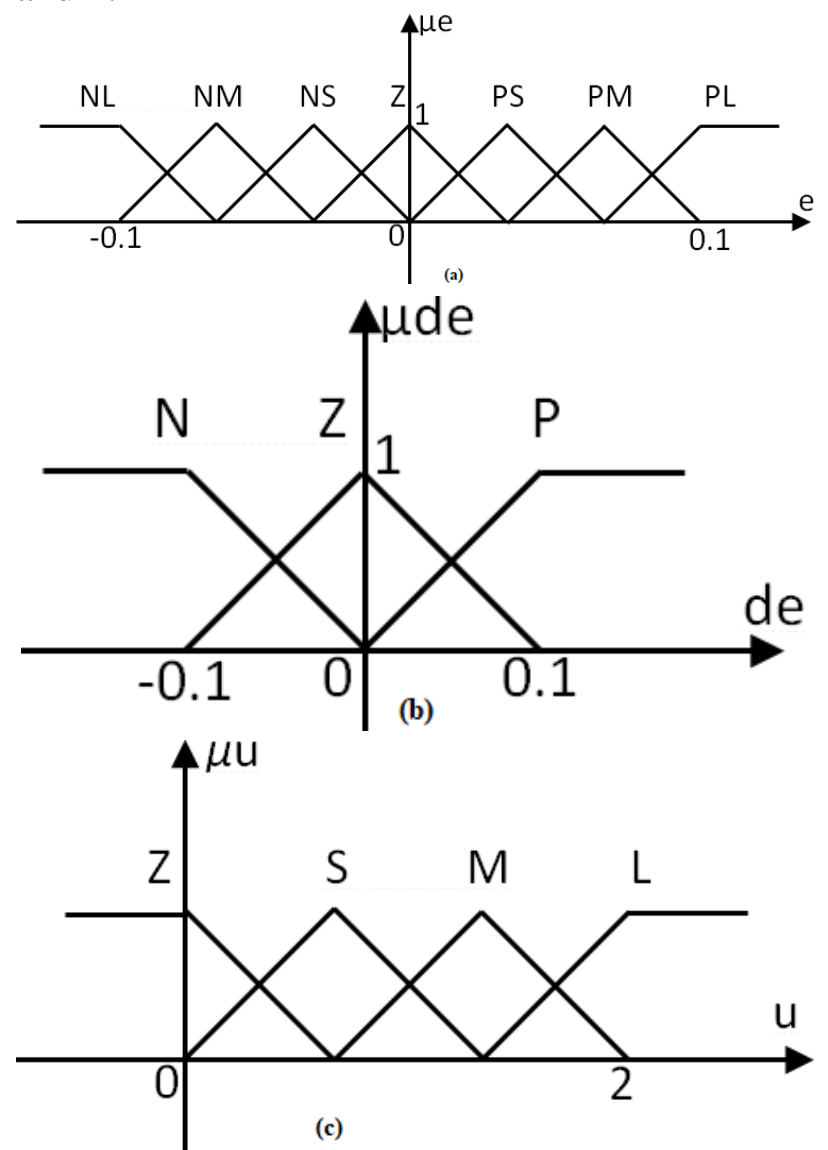

Figure 4. a. Membership function of speed error $b$. Membership function of change in speed error $\mathrm{c}$. Membership function of output

Table 3. Rule table for $\Delta K_{p}$

\begin{tabular}{|c|c|c|c|c|c|c|c|}
\hline & NL & $\mathrm{NM}$ & NS & $\mathrm{Z}$ & PS & $\mathrm{PM}$ & PL \\
\hline $\mathrm{N}$ & $\mathrm{L}$ & $\bar{M}$ & $\mathrm{~S}$ & $\bar{M}$ & $\mathrm{~S}$ & $\bar{M}$ & $\mathrm{~L}$ \\
\hline $\mathrm{Z}$ & $\mathrm{L}$ & $\mathrm{M}$ & $\mathrm{L}$ & $\mathrm{Z}$ & $\mathrm{L}$ & $\mathrm{M}$ & $\mathrm{L}$ \\
\hline $\mathrm{P}$ & $\mathrm{L}$ & $\mathrm{M}$ & $\mathrm{L}$ & $\mathrm{Z}$ & $\mathrm{L}$ & $\mathrm{M}$ & $\mathrm{L}$ \\
\hline
\end{tabular}

Table 4. Rule table for $\Delta K_{I}$

\begin{tabular}{l|lllllll}
\hline de & NL & NM & NS & Z & PS & PM & PL \\
\hline $\mathrm{N}$ & $\mathrm{Z}$ & $\mathrm{K}$ & $\mathrm{M}$ & $\mathrm{L}$ & $\mathrm{M}$ & $\mathrm{K}$ & $\mathrm{Z}$ \\
$\mathrm{Z}$ & $\mathrm{Z}$ & $\mathrm{K}$ & $\mathrm{M}$ & $\mathrm{L}$ & $\mathrm{M}$ & $\mathrm{K}$ & $\mathrm{Z}$ \\
$\mathrm{P}$ & $\mathrm{Z}$ & $\mathrm{M}$ & $\mathrm{L}$ & $\mathrm{L}$ & $\mathrm{L}$ & $\mathrm{M}$ & $\mathrm{Z}$ \\
\hline
\end{tabular}

The new $\Delta K_{p}$ and $\Delta K_{I}$ values obtained at the output of the fuzzy logic controller are given below.

$K_{p}(k)=K_{p}(k-1)+\Delta K_{p}$

$K_{I}(k)=K_{I}(k-1)+\Delta K_{I}$

\subsubsection{Sliding mode controller}

The sliding mode controller is good for speed control as it is insensitive to system uncertainties and disturbing effects such as change in rotor time constant and change in stator resistance.

Sliding mode is a method used for variable structure systems. A variable structure system can be written as below. Here $\dot{x}$ is derivative form of $x$.

$\dot{x}=f(x, t, u), x \in R^{n}, u \in R^{m}$

$u= \begin{cases}u^{+}(x, t) & \sigma(x)>0 \\ u^{-}(x, t) & \sigma(x)>0\end{cases}$

$\sigma^{T}=\left(\sigma_{1}, \ldots \sigma_{m}\right)$

For this system, in the state space, the discontinuous control input for $\sigma=0$ forms the sliding surfaces. The resulting new system is expressed by a sliding mode equation with (n$\mathrm{m})$ degree. In order to achieve this equation in sliding mode, the control input must be replaced with the expression "equivalent control". The new control signal is obtained by solving Equation (13).

$\sigma=C e+\dot{e},(\mathrm{C}>0)$

The sliding surface given by the above equation expresses the relationship between system state variables and system dynamics. As a result of discontinuous switching process, it is conceivable that the signal will ideally go to infinity in torque of space in switching. However, due to the internal and external disturbance dynamics of the system, the gain is prevented from going to infinity. As a result, the switching process eliminates disturbing effect. In order to eliminate the disturbance effect, it is necessary to limit the parameters by defining a boundary layer around the sliding mode, given that the time constant is omitted in the noncontinuous ideal control signal. As a result of this process, robust control approach is obtained.

$\dot{x}=f(x, t)+B(x, t) u$

A control system of this structure can be provided with the separation using the sliding mode equation whose degree is reduced and which is non-bound to the control signal (u), as given in Equation (15).

$\dot{x}=f_{1}\left[x_{1}, t, \sigma_{0}\left(x_{1}\right)\right], f_{1} \in R^{n-m}$

For this purpose, it is necessary to first express the appropriate sliding mode surface $\sigma(x)$ or $\sigma_{0}\left(x_{1}\right)$ functions. It is then necessary to have a suitable discontinuous control signal to ensure system stability. 


\subsection{Speed estimation}

Sensors are used to measure speed and position, which are important parameters in motor control. However, sensorless study is suggested because of higher reliability and lower cost. In this study, MRAS and sliding mode observers were studied for speed estimation.

\subsubsection{Model Reference Adaptive System}

In MRAS observer, the PMSM is considered as the reference model and the current model of the motor with speed expression is considered as the adaptive model. The rotor speed and position can be determined by the adaptive method [20]. Current model of the motor can be written as below.

$\frac{d i_{d}}{d t}=\frac{-R_{s}}{L_{s}} i_{d}+\omega i_{q}+\frac{1}{L_{s}} \frac{d V_{d}}{d t}$

$\frac{d i_{q}}{d t}=-\omega i_{d}-\frac{R_{s}}{L_{s}} i_{q}+\frac{1}{L_{s}} \frac{d V_{q}}{d t}$

Speed estimation can be defined as follows (The hat in the symbol means that the variable is estimated) [24, 25].

$\frac{d \hat{\imath}_{d}^{\prime}}{d t}=\frac{-R_{S}}{L_{s}} \hat{\imath}_{d}^{\prime}+\omega \hat{\imath}_{q}^{\prime}+\frac{1}{L_{s}} \frac{d V_{d}^{\prime}}{d t}$

$\frac{d \hat{\imath}_{d}^{\prime}}{d t}=-\omega \hat{\imath}_{d}^{\prime}-\frac{R_{s}}{L_{s}} \hat{\imath}_{q}^{\prime}+\frac{1}{L_{s}} \frac{d V_{q}^{\prime}}{d t}$

$\widehat{\omega}=\int k_{1}\left(i_{d}^{\prime} \hat{\imath}_{q}^{\prime}-i_{q}^{\prime} \hat{\imath}_{d}^{\prime}\right) d \tau+k_{2}\left(i_{d}^{\prime} \hat{\imath}_{q}^{\prime}-i_{q}^{\prime} \hat{\imath}_{d}^{\prime}\right)+$ $\widehat{\omega}(0), k_{1}, k_{2} \geq 0$

Here;

$\hat{\imath}_{d}^{\prime}=i_{d}+\frac{\psi_{r}}{L_{s}}, \hat{\imath}_{q}^{\prime}=i_{q}$

$\widehat{V}_{d}^{\prime}=V_{d}+\frac{R_{s} \psi_{r}}{L_{s}}, \widehat{V}_{q}^{\prime}=V_{q}$

\subsubsection{Sliding mode observer}

Another observer used in speed estimation is the sliding mode observer. The necessary explanations for the sliding mode method are given in Section 2.3. Using Equation 10, 11 and 12 and Figure 5, speed estimation can be realized.

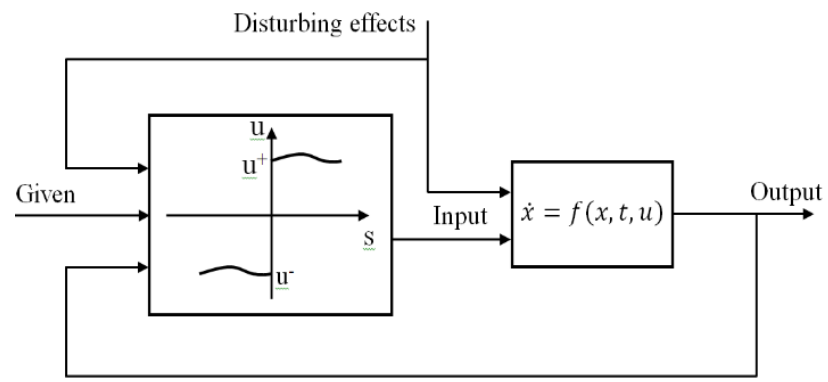

Figure 5. Structure of sliding mode observer

\section{Simulation Results}

In this study, direct torque controlled PMSM was performed in MATLAB by using different speed control methods and speed estimation methods. DTC is the most suitable method for controlling the torque and flux of the motor having a complex structure separately. The motor speed is required to carry out the DTC. It can be determined using speed sensor or speed estimation methods without using a speed sensor. In this study, both speed sensor and speed sensorless study were performed with two different speed estimation methods (MRAS and SMO). The speed information obtained with or without the sensor must be passed through the speed controller for more stable operation of PMSM, before it is transferred to the DTC algorithm. In this study, three different speed controllers were used for this purpose (PI, fuzzy logic a sliding mode controller).

In this study, DTC of the PMSM for electric vehicles has been realized in 2 different cases, with and without speed sensor. The parameters of the PMSM used in the study are given in Table 5. In the simulation study, ECE-15 Urban Drive Cycle was applied as speed reference to PMSM. Firstly, the performance of the speed control methods was evaluated with sensor. Then, the performance of speed estimation methods was compared by applying sensorless application.

Table 5. parameters of PMSM

\begin{tabular}{ll}
\hline Description & Specifications \\
\hline Power & $3.9 \mathrm{~kW}$ \\
Nominal Torque & $12.5 \mathrm{Nm}$ \\
Nominal speed & $3000 \mathrm{rpm}$ \\
Pole number & 6 \\
Stator resistance & $0.3 \Omega$ \\
d axis inductance & $8.5 \mathrm{mH}$ \\
q axis inductance & $8.5 \mathrm{mH}$ \\
Magnet flux & $0.185 \mathrm{~Wb}$ \\
Inertia & $0.0755 \mathrm{kgm}^{2}$ \\
\hline
\end{tabular}

Firstly, PI, fuzzy logic and sliding mode speed controller are used as speed control of PMSM with speed sensor and the speed, torque, consumed energy and current of phase A graphs for each controller are given below.

Figure 6 shows the speed variation for three different speed controllers of the PMSM. According to the speed graph, it is clear that the measured speed which is closest to the reference speed is acquired from the sliding mode controller, then the fuzzy logic controller and 
finally the PI controller. The sliding mode controller shows that the performance is high in the part where both the speed reference changes and is constant. Figure 7 shows the torque graphs for three different methods. As it can be understood from the torque graphs, the controller with the least ripple in the torque is the sliding mode control, then the fuzzy logic and the controller with in the highest ripple in torque is PI controller. It is clear that the sliding mode controller has the best robustness. It is sliding mode controller that gives the best results in torque like speed graphs. Figure 8 shows the graphs of energy consumed for three different speed control methods. At the end of the simulation study, $4.1205 \mathrm{~kJ}$ energy was consumed in PI controller, $4.1102 \mathrm{~kJ}$ in fuzzy controller and $4.1056 \mathrm{~kJ}$ in sliding mode controller. The least energy consumption is consumed in the sliding mode controller, then the fuzzy logic controller and the maximum consumption is in the PI controller. As a result, less ripple means less energy consumption. Figure 9 shows the current graphs for three different methods. According to current figure, ripples in current graph for sliding mode controller are lower than other control methods which are PI and fuzzy logic controller.

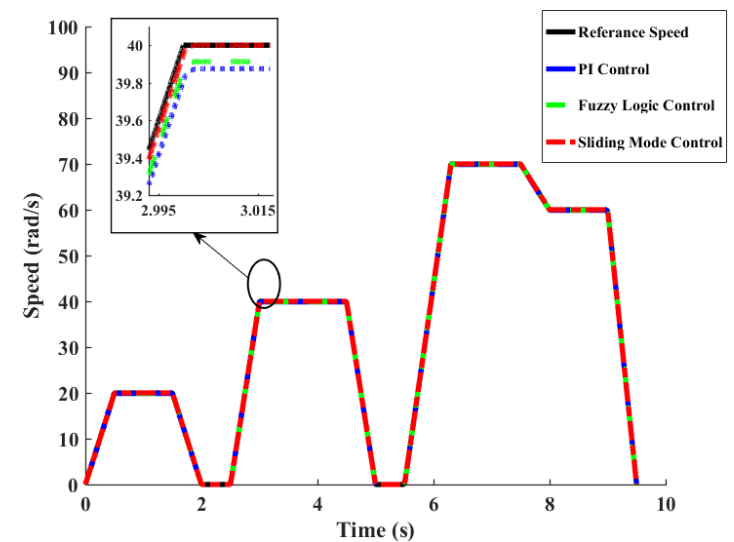

Figure 6. Speed of PMSM for three speed controllers

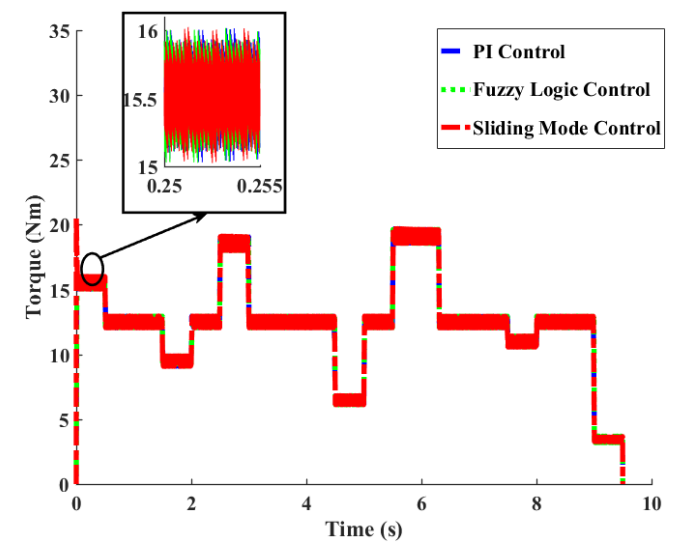

Figure 7. Torque of PMSM for three speed controllers
In the second part of the study, the speed sensorless study of the PMSM was carried out at nominal load using MRAS and sliding mode observer and the speed, speed error, torque, and consumed energy graphs for each observer are given below.

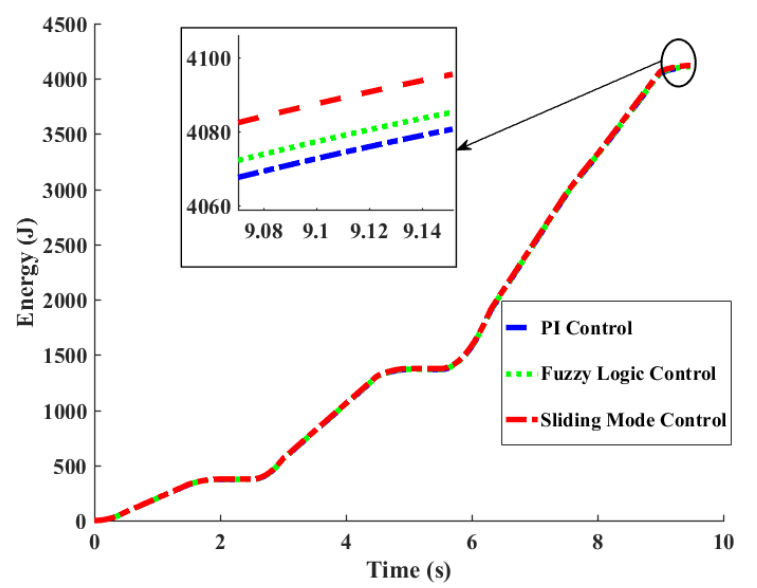

Figure 8. Energy of PMSM for three speed controllers

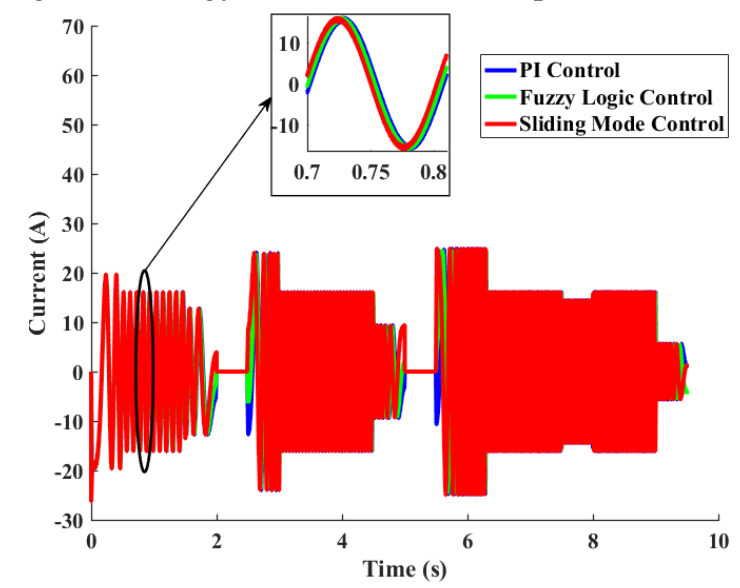

Figure 9. Current of phase A of PMSM for three speed controllers

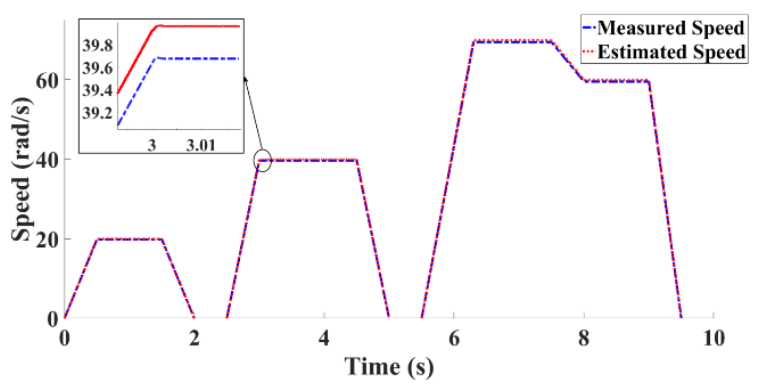

Figure 10. Measured and estimated speed for MRAS observer

Figure 10 and 11 illustrate the speed changes for the two speed observers of the PMSM. According to the speed graph, it is clear that the method that best predicts the measured speed is a sliding mode observer and then MRAS. Furthermore, the speed error of the sliding mode observer as shown in Figure 12 is less than the error of MRAS. Figure 13 shows the torque graphs for two different speed observers. As it 
can be seen from the torque graphs, the observer where the torque ripple is minimal is the sliding mode observer and then the MRAS observer. Figure 14 shows the energy consumed for two different speed observers. At the end of the simulation study, $4.1197 \mathrm{~kJ}$ energy was consumed in sliding mode observer and 4.1617 $\mathrm{kJ}$ in MRAS observer. It is sliding mode observer that gives the best results in energy consumption as well as in torque and speed graphs. The least energy consumption is consumed in the sliding mode observer and the highest in MRAS observer.

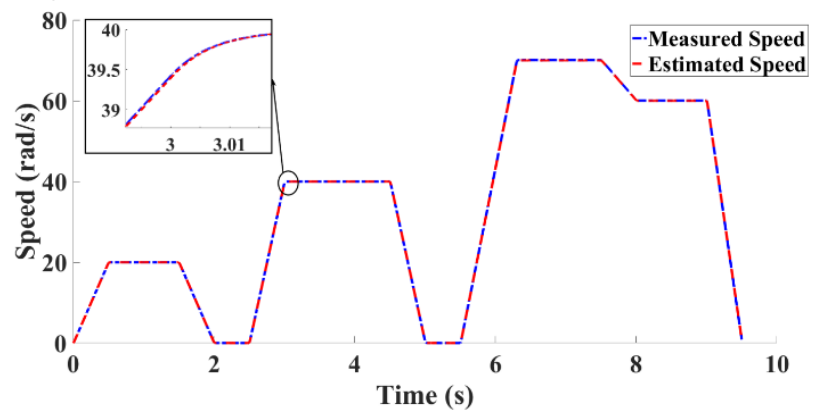

Figure 11. Measured and estimated speed for sliding mode observer

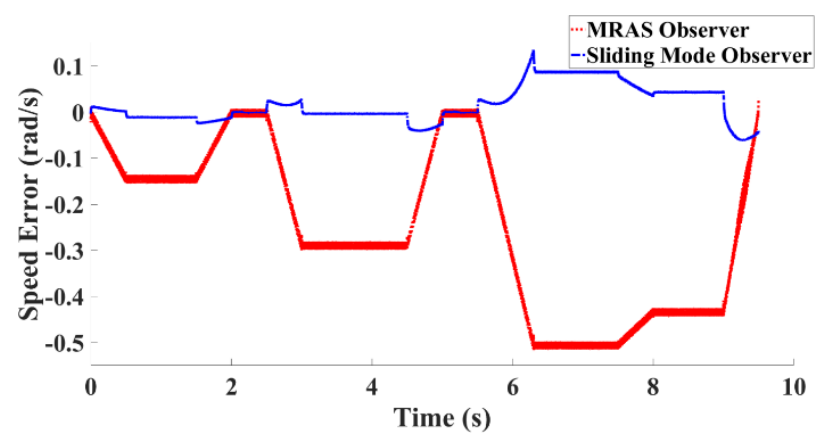

Figure 12. Speed error for two speed observers

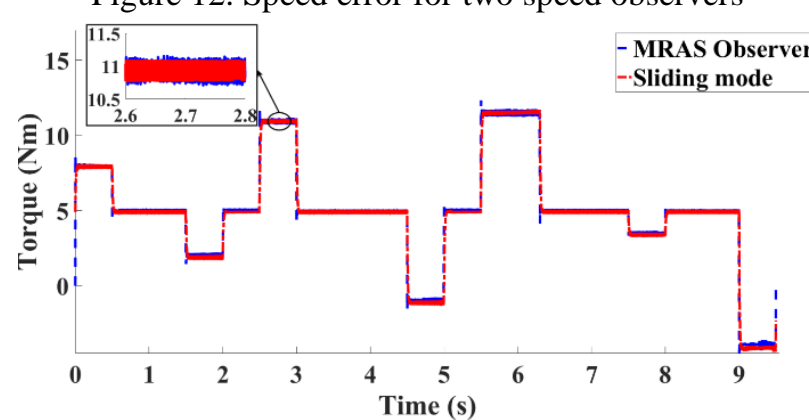

Figure 13. Torque graphs for two speed observers

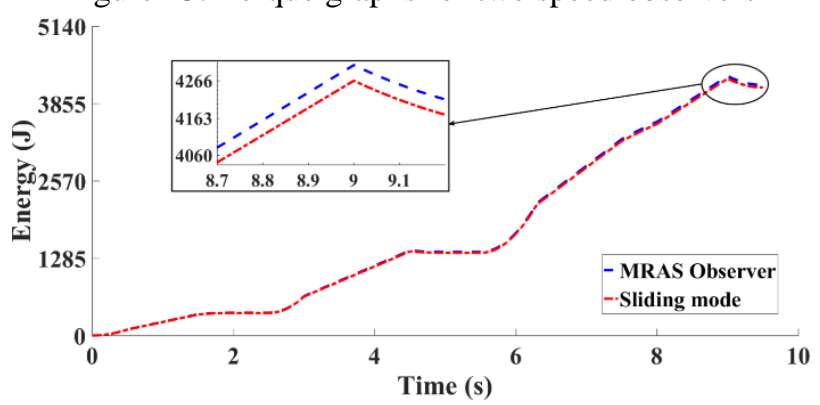

Figure 14. Energy consumption graph for two speed observers

\section{Conclusions}

In electric vehicle applications, ripples in torque, current and flux should not be excessive. Otherwise, motor performance and maintenance costs can be affected negatively. For this purpose, in this study, the performance of different speed controllers and observers in DTC of PMSM used in electric vehicles was evaluated. Compared with other speed control methods which are PI and fuzzy logic, it has been found that the sliding mode speed controller performs better than others in speed control. Furthermore, when the torque, current and energy figures are examined, the sliding mode controller is more robust. It provides less ripples and energy consumption. In addition, when the sliding mode observer was used, the rotor speed was estimated more accurately, the torque ripple and energy consumption was less.

\section{References}

1. M. R. Hachicha, M. Ghariani and R. Neji, "Induction machine DTC optimization using artificial intelligence for EV's applications", Eighth International MultiConference on Systems, Signals \& Devices, Sousse, 2011.

2. M. Abassi, A. Khlaief, O. Saadaoui, A. Chaari and M. Boussak, "Performance analysis of FOC and DTC for PMSM drives using SVPWM technique", 2015 16th International Conference on Sciences and Techniques of Automatic Control and Computer Engineering (STA), pp. 228-233, Monastir, 2015.

3. V. M. Bida, D. V. Samokhvalov and F. S. Al-Mahturi, "PMSM vector control techniques-A survey", IEEE Conference of Russian Young Researchers in Electrical and Electronic Engineering (EIConRus), pp. 577581, Moscow, 2018.

4. Kronberg, "Design and simulation of field oriented control and irect torque control for a permanent magnet synchronous motor with positive saliency", Thesis for M.S. degree, Uppsala university, May 2012.

5. Y. Yue, R. Zhang, B. Wu and W. Shao, "Direct Torque Control Method of PMSM Based on Fractional Order PID Controller", IEEE 6th Data Driven Control and Learning Systems Conference May 26-27, Chongqing, China, 2017.

6. M. Omara, M. Sleptsov, A. A. Z. Diab, 
"Cascaded Fuzzy Logic Based Direct Torque Control of Interior Permanent Magnet Synchronous Motor for Variable Speed Electric Drive Systems", 25th International Workshop on Electric Drives: Optimization in Control of Electric Drives (IWED), Moscow, Russia, Jan 31-Feb 02, 2018.

7. Ameur, B. Mokhtari, N. Essounbouli, and L. Mokrani, "Speed Sensorless Direct Torque Control of a PMSM Drive using Space Vector Modulation Based MRAS and Stator Resistance Estimator", International Scholarly and Scientific Research \& Innovation 6(6), pp. 198-203, 2012.

8. Y. K. H. Dan Sun, Jian Guo Zhu, "Direct Torque Control of a Permanent Magnet Synchronous Motor", Aupec, pp. 3358-3361, 2002.

9. J. Liu-, W. Wang and Y. Wang, "Research on FOC and DTC switching control of asynchronous motor based on parameter estimation", IEEE International Conference on Automation and Logistics, Qingdao, pp. 17541758, 2008.

10. J. Thomas K. René A.A. Melkebeek "Direct Torque Of Permanent Magnet Synchronous Motors-An Overview", 3rd IEEE, April 2006.

11. M. Kadjoudj, S. Taibi N. Golea, H. Benbouzid, "Modified Direct Torque Control of Permanent Magnet Synchronous Motor Drives", International Journal of Sciences and Techniques of Automatic control \& computer engineering, Volume 1, No. 2, December 2007, pp. 167-180.

12. Carlos Canudas de Wit, "Modélisation contrôle vectoriel et DTC", Hermes Science Europe Ltd, 2000.

13. F. Korkmaz, İ. Topaloğlu, M. F. Çakir and R. Gürbüz, "Comparative performance evaluation of FOC and DTC controlled PMSM drives", 4th International Conference on Power Engineering, Energy and Electrical Drives, pp. 705-708, Istanbul, 2013.

14. Ling,W. Zhao and S. Bing "The Direct Torque Control (DTC) of the Permanent Magnet Synchronous Motor (PMSM) based on the Nonsingular Terminal Sliding Mode (NTSM)", International Conference on Modelling, Identification and Control, Wuhan, China, June 24-26, 2012.

15. S. P. Bhat and D. S. Bernstein, "Finite- time stability of homogeneous systems", Proceedings of American Control Conference, pp. 2513-2514, 1997.

16. S. P. Bhat and D. S. Bernstein, "Continuous finite-time stabilization of the translational and rotational double integrator", IEEE Trans. Autom. Control, vol.43, no.5, pp.678-682, 1998.

17. G. Shahgholian, M. H. Rezaei, A. Etesami, M. R. Yousefi "Simulation of Speed Sensor Less Control of PMSM Based on DTC Method with MRAS", Proceeding of the IEEE/IPEC, pp.40-45, October, 2010.

18. Li Yongdong and Zhu Hao, "Sensorless Control of Permanent Magnet Synchronous Motor-A Survey", IEEE Vehicle Power and Propulsion Conference (VPPC), Harbin, China, September 3-5, 2008.

19. K. Rajashekara, A. Kawamura and K. Matsuse, "Sensorless Control of AC Motor Drives", IEEE Press, 1996.

20. J. Hole, "State of the Art of Controlled AC Drives without Speed Sensors", Int.J.Electronics, vol.80, No.2, pp.249-263, 1996.

21. Y. Ohm, J.W. Brown, and V. B. Chava, "Modeling and parameter characterization of permanent magnet synchronous motors", in Annual Symposium of Incremental Motion Control Systems and Devices, 1995.

22. Takahashi, T. Noguchi, "A New QuickResponse and High-Efficiency Control Strategy of an Induction Motor", IEEE Trans. Ind. Appl., vol. IA-22, no. 5, pp. 820-827, Sept./Oct. 1986. 23. L. A. Zadeh, "Fuzzy Sets. Information and Control", vol. 8, pp. 338-353, 1965.

24. Y. S. Han, J. S. Choi and Y. S. Kim, "Sensorless PMSM Drive with a Sliding Mode Control Based Adaptive Speed and Stator Resistance Estimator", IEEE Transactions on magnetics, vol.36, no.5, pp. 3588-3591, September, 2000.

25. Y. S. Kim, S. K. Kim, Y. A. Kwon, "MRAS Based Sensorless control of permanent magnet synchronous motor", SICE Annual conference in Fukui, August 4-6, 2003. 